small area of the Purbeck beds revealed their presence in numbers ; had this spot not been quarried it would have been supposed for years that mammalia had made their appearance in Eocene times. Some causes, tending to make the preservation of dicotyledons difficult were discussed in NATURE, vol. xv. p. $28 \mathrm{r}$, and need not be further alluded to here. Mere localised patches of plant remains are not an unerring index of the character of a flora at any period. At Bournemouth there are patches just underlying the lowest marine beds, which are crowded with ferns only; other patches contain nothing but ferns, aroids, and gymnosperms. Had these patches been isolated, inferences of a most misleading character would have been drawn.

The upper Cretaceous floras are known to us principally from Aix-la. Chapelle and from America; but as in both these-indeed in most cases--the supposed Cretaceous beds containing plant remains rest on palæozoic rocks, their relative age is a matter of uncertainty. M. Barrois fixes it as contemporaneous with his zone of Belemnitella, but whether he is right in this supposition or not, the flora contains ferns and other plants which seem identical with those of the Bournemouth beds. In America, in the Dakota group, we have leaf beds 400 feet thick of the supposed age of our gray chalk, but the associated marine beds have, mixed with decidedly Cretaceous forms, shells approaching very closely those of our London clay. It seems more logical to determine the age of a rock by the incoming of new types than by the lingering of old, and the whole palæontological evidence shows that these beds are at most intermediate in age between our Eocene and Chalk, the enormous gap between which is probably filled up here by some 2,200 feet of strata. American geologists are not agreed as to their age. It would be out of place to discuss this subject at length, but enough is said to show that the relative ages of these floras is not definitely known, and that no series of arguments based on their relaive sequence is, at present, entitled to any weight. $M$. Lesquerenx finds evidence in support of evolution in the flora of Dakota, "in the remarkable disproportion of genera compared to species ;" and in the sameness of the leaves, which are "mosily entire, coarsely veined, and coriaceous, the difficulty of separating them into distinct groups, by fixed characters, the numerous forms of leaf which, seen separately, represent different species, or even genera, and which, considered in series or groups, appear undividable into sections." When, however, he theorises, we see that he makes use of the same arguments against evolution as those put forward by Mr. Carruthers. Von Ettingshausen, on the other hand, who has paid much attention to the subject, states that he is able to trace the ancestry of our present floras back to simple elements in Tertiary times, and these to still simpler and more united types in Cretaceous times. In his works a number of examples are given. The flora of Sezanne, whose age as Lower Eocene may be accepted, is closely analagous with that of Bournemouth.

Now let us examine the manner in which determinations of fossil leaves from these earlier rocks have been made, and see whether they are sufficiently reliable to entitle us to form any theories whatever as to the simnltaneous appearance of the three divisions of Dicotyledons. Let us take the flora of Dakota.

Of Polypetale we have Liriodendron, founded on two fragments, and Magnolia on two fragments. These fragments are of simple leaves and possess no character whatever in themselves, apon which they can be determined. Magnolia, for instance, is determined from the similarity in form to leaves described as Magnolia by Heer in the Flora of Greenland, which themselves are supposed to be Magnolia because they resemble (not specifi. cally) Magnolias from the Miocene of Europe. In Menespermites, the third genus, the name indicates that its affinities are vague, and we accordingly see that it had been formerly described as Dombeyopsis, Acer, Populites. The Gamopetalo are represented by three genera. Of these Andromeda is determined on two fragments and one indistinct leaf of simple lanceolate form; Diospyros, formerly described as Quercus, is determined from one simple and ovate leaf resembing Laurus, the other a round and simple leaf; while Brumelia is still more unsatisfactory, and has been previously thought to be either Laurus or Quercus. The determinations have been changed, as we see by the position of the plates and the figures on the plates, many times during the progress of the work, and it is not too much to say that all the determinations of leaves of Polypetalie and Gamopetalæe from this flora are vague and unsatisfactory, and no one would be more ready to acknowledge this than Mr. Carruthers himself. We do not find fanlt so much with the determinations themselves, which are probably the best that could be made from such material, but we think it premattre to base any theories upon them as to the simultaneous appearance with the Apetalæ of the more highly organised Dicotyledons.

In the Eocene and Miocene we have, however, richer materials, and the variety and completeness of the fossil flora become conspicuous; the forms, as Lyell says, "were perfect, changing, but always becoming more and more like, generically and specifically, to those now living." Von Ettingshausen has traced the direct descent of many living species back to the Miocene, sometimes two or more species to a common parent stock.

5. With regard to the persistence of Salix polar is, it appears to be simply a case of a plant becoming thoroughly adapted to certain conditions of life which were met wilh in. England during the glacial period, and are present now in extreme northern regions. Why Salix polaris should have varied since glacial times more than mollusca and other animal life is not apparent. The intermediate forms which should connect willows and poplars have not been found, but as poplar-like leaves have been met with in lower cretaceous rocks, it is probable that the order of Salicacer is an extremely ancient one, and the single generalised form must be sought for in remoter times even than the Cretaceous.

Our general broad knowledge of the succession of plant life, as testified by the rocks, is too well known to need recapitulating here. Schimper enters in detail into its history. In the Silurian, Alga; in the Devonian ferns and Lycopods, reaching their apogee of development in the Carboniferous ; and in the Permian the conifers first take an important position. The Triassic indicates a great gap, and may be considered the reign of gymnosperms, whilst the incoming of the phanerogams is placed beyond doubt. The Jurassic presents another hiatus, and but little is known of its flora. ${ }^{1}$ Heer, however, infers, from the entomological fauna, that there were no leafy trees in the Lias. The oolitic rocks contain abundance of cycads. The Wealden and Neocomian vegetation has left us little more than gymnosperms and ferns. With the upper cretaceous period dicotyledons are abundant, but their incoming is traced to older rocks. The Eocene contains rich assemblages of dicotyledons, principally apetalous, and the Miocene, better known, a still greater variety. We see the same plan of development in the individual; and, as Prof. Huxley recently stated in a lecture at South Kensington, "we can trace living plants from the most gigantic and complicated tree, step by step down through many gradations to the lowest algæ, the lichens, and on down to a piece of animal jelly."

Thus we find on reviewing the evidence that has been brought forward, that other interpretations may be put upon the facts presented to us by Mr. Carruthers.

IN an article in this month's Contemporary, entitled "Evolution and the Vegetable Kingdom," Mr. Carruthers refers incidentally to a question that deserves the careful consideration of all who accept the doctrine of evolution; viz., whether the earliest type of flower was hermaphrodite or unisexual. Alluding to the abundance and variety of palzozoic gymnosperms, as evidenced by the numerous fruits that have been discovered in the carboniferous measures, he lays stress on the fact that "they all belong to the Taxineous group of conifers... . that the plants of this section are all dicecious, $i$.e. having the sexes on different plants. If the occurrence of the germ and sperm elements in different organs, and even in different individuals, is evidence, as it is held, of higher development in phanerogams, then it is important to notice the order of appearance of dioccious and monoecious groups in relation to those with hermaphrodite flowers. Advocates of evolution hold that dimorphic plants are now in a transition stage progressing towards a diocious condition. The conifers attained to the highest known development as regards this element of their structure on their first appearance."

If Mr. Darwin be regarded as an exponent of the views held by "advocates of evolution," we find that he expresses himself very differently. From the following passages in his recently published work on "The Effects of Cross and Self-fertilisation in the Vegetable Kingdom," he would seem to consider the primordial condition to be unisexual. "There is good reason to believe that the first plants which appeared on this earth were crypto. gamic. .... As soon as plants became phanerogamic and grew on the dry ground, if they were to intercross, it would be indispensable that the male fertilising element should be trans. ported by some means through the air; and the wind is the r An extensive Jurassic flora has been described by Heer in Mém. de ז 876 . 
simplest means of transport." ... "Therefore the Conifera and Cicadire, no doubt, were anemophilous, like the existing species of these groups." . . . "A remarkable fact with respect to anemophilous plants is that they are oten diclinous." For reasons which he gives, Mr. Darwin considers that this "may be attributed to anemophilous plants having retained, in a greater degree than the entomophilous, a primordial condition, in which the sexes were separated and their mutual fertilisation effected by means of the wind." ... " If this view is correct, plants must have been rendered hermaphrodites at a later though still very early period, and entomophilous at a yet later period, namely, after the development of winged insects." He subsequently points out, however, that " under changing conditions of life.... some bermaphrodite plants, descended, as we must believe, from aboriginally diclinous plants, have had their sexes again separated " and he names as an example, Lychnis dioica. It is only in the case of plants thus reverting that dimorphism can be held to be a transitional stage.

Prof. Thiselton Dyer, in his notice of Mr. Darwin's book in NATURE (vol. xv., p. 329), maintains an opposite view. "It would not be difficult to show that all through the vegetable kingdom the hermaphrodite condition precedes the dicecious." Demurring to Mr. Darwin's conclusion that the monoecious condition "is probably the first step towards hermaphroditism," he considers it "not improbable that precisely the converse may be more true." : . . . "To throw light on the question whether the primordial plant was diclinous or not," he discusses the manner in which it probably originated "from some plant-form not dis. tantly relatecl to Selaginella," and arrives at the conclusion that the first flower would probably be extremely inconspicuous, destitute of colour and hermaphrodite.

How would it be, however, if, instead of regarding the sporangiiferous cone or spike of Selaginella as the homologue of a single flower, we compare it rather with the spike of Carex, say, for example, C. pulicaris? The spike in this species is, like the other, "composed essentially of an axis having modified lateral appendages." The glumes of the sedge correspond to the scales of the lycopod; in the axils of the upper are found the "male structures"--in Selaginella, sporangia containing microspores; in Carex, anthers containing pollen; in the axils of the lower are found the "female structures"-in Selaginella, sporangia containing macrospores; in Carex, ovaries containing each an ovule. There is then not even the difference that the position on the axis of the male and female structures is inverted. From C.pulicaris, with its single spike, the passage is easy 10 species that have several spikelets, each inale at the top and $\mathrm{ftmale}$ below ; or to others that have the upeer spilielets wholly male, the lower ones wholly female. The same arrangement of male and female elements is found in Typha and Sparganium, in most of the Aracex, to which order belong the oldest fossil monocotyledons, and is preserved even in Sagittaria, although in the last the flowers are of a much higher type, being provided with petalloid perianths. So far as the comparison with Selaginella is concemed, does it not favour the production in the first place of unisexual flowers, at least as much as of hermaphrodite?

Newton le Willows

The Rocks of Charnwood Forest

SOnE letters appcared in NATURE a few months ago upon the rocks of Charnwood Forest. In one of them it was suggested that the syenitic bosses of Markfield and Groby might be more ancient than the surrounding slates and grits. Some of jour readers may therefore be interested in learning that we have now ascertained from unquestionable evidence in two places that the syenite is intrusive in these rocks, and, as we believe, in some of the highest and latest rocks of the series. We reserve the details of the sections and localities for a paper which we hope shortly to communicate to the Geological Society.
St. John's College, Cambridge,
March 20
T. G. BONNEY
E. IHILL

\section{Southern Double Stars}

Noting some queties in your November numbers (in the "Astronomical Column") respecting some soutiern stars, I inclose you some extracts from our occasional observations that refer to the objects named in those and some previous numbers :-
Southern Double Stars.-Measures wilh 8-inch Refractor.

\begin{tabular}{|c|c|c|c|c|c|}
\hline & Pos. & bit. & $\begin{array}{l}\text { No. } \\
\text { Obs. }\end{array}$ & Epoch. & \\
\hline 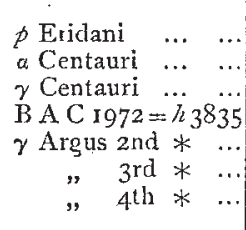 & $\left\{\begin{array}{c}0 \\
237 \cdot 3 \\
50 \cdot 6 \\
8 \cdot 5(?+180) \\
10 \cdot 0 \\
214.8 \\
151 \cdot 1 \\
141 \cdot 3\end{array}\right.$ & $\mid$\begin{tabular}{c|}
11 \\
5 \\
$3 \cdot 9$ \\
$1 \cdot 3$ \\
$2 \cdot 1$ \\
$42 \cdot 5$ \\
$62 \cdot 6$ \\
$94 \cdot 3$
\end{tabular} & $\left.\begin{array}{l}2 \\
3 \\
1 \\
5 \\
2 \\
2 \\
2\end{array}\right\}$ & $\begin{array}{r}1877.03 \\
1876.72 \\
1876.63 \\
1876.98 \\
1877.03\end{array}$ & $\begin{array}{c}\text { Magni- } \\
\text { rudes } \\
2-4 \frac{1}{3}-8-9 \frac{1}{8}\end{array}$ \\
\hline
\end{tabular}

Melbourne Observatory, January 22

RobT. L. J. Ellery

\section{Ship's Chronometers}

WE have read with much pleasure your notice (vol. xv. p. 403) of Sir William Thomson's lecture on Navigation, and are prepared fully to endorse your remarks as to the value of Mr. Hartnup's system of rating ships' chronometers, by which account is taken of the change of rate due to change of tem. perature.

It is but fair to mention, however, that the principle upon which this system is founded was thoroughly investigated by experiments upon a large number of chronometers by $M$. Lieusons, of Paris, some thirty or forty years ago; acting upon his suggestions, and after independent investigation conducted in our chronometer manufactory some six years ago, we produced a table for the use of captains and others using ships' chronometers, which was fastened in the chronometer case, with a small thermometer in front of it, in such a way that the top or upper end of the column of mercury indicated, without any calculation whatever, the mean rate that should be given every day to the chronometer until some considerable change of temperature had taken place (say $3^{\circ}$ ), when the new position of the top of the mercury column again showed the new rate to be used in working the chronometer.

We did not introduce this plan to the navigating public generally, as we feared that sufficient trouble (small though it actually be) would not have been taken in the use of it, also for another reason, i.e., nearly every chronometer that we have tested has been tound to require a different daily coefficient for a change of temperature of $\pm^{2} I^{\circ}$, and ships rarely remain sufficient time in port for us to determine this coefficient after allowing for the time necessary to clean the chronometer.

But, as our system of tabulation may be of interest to your readers and may possibly be available for otler purposes, we give it you as briefly as possible.

From our experience (which agrees with that of Lieusous and of Hartnup) we find that the ordinary compensation balance without auxiliary, causes the chronometer to go at its fastest rate (or in other words to lose least) at a point of the thermometric scale somewhere between $55^{\circ}$ and $70^{\circ} \mathrm{F}$, usually at $60^{\circ}$ or $65^{\circ}$, and that from $25^{\circ}$ to $30^{\circ}$ above or below that "fastest point" the chronometer loses or goes slower on its fastest rate by an amount that is determined by multiplying the square of the difference in temperature between the new point and the "fastest point" by the coefficient of temperature for a change of $1^{\circ}$ above or below the "fastest point," i.e., by the amount that a chronometer goes slower for having its temperature increased or diminished by $1^{\circ}$.

This is, however, only true so long as two conditions are adhered to ; the first condition being that the "fastest point" (which can be moved at will by the chronometer maker), shall not be taken outside the limits of $55^{\circ}$ to $70^{\circ}$, that is, the rule will apply from $30^{\circ}$ to $95^{\circ}$ but not beyond, even though the "fastest point" should be moved up to $80^{\circ}$ or down to $40^{\circ}$; beyond these points a new law applies, and instead of squaring the difference of temperature and multiplying that quantity by the coefficient of temperature, this latter must be multiplied by the difference of temperature (always reckoned from the "fastest point" of the chronometer under trial) raised to a power between the square and the cube, or $x \frac{5}{2}$, for which good reasons can be given.

This being explained, it will be easy to perceive the the of the 